\title{
PENGGUNAAN PUPUK KOMPOS DAN PUPUK FOSFOR TERHADAP PERTUMBUHAN TANAMAN KACANG HIJAU
}

\author{
Suratmin $^{1}$, Deli Wakano ${ }^{2}$, Dahlia Badwi ${ }^{3}$ \\ 1,Program Studi Pendidikan Biologi IAIN Ambon \\ ${ }^{2}$ Program Studi MIPA Biologi Unpatti Ambon \\ ${ }^{3}$ Program Studi Pendidikan Biologi Universitas Darusalam Ambon \\ E-mail: suratmin123@yahoo.co.id
}

\begin{abstract}
Abstrak: Hasil penelitian menunjukan bahwa pemberian pupuk kompos dan pupuk fosfor berpengaruh secara nyata pada pertumbuhan tanaman kacang hijau yang meliputi beberapa parameter tanaman (tinggi tanaman dan luas daun tanaman) begitu juga dengan interaksi antara pupuk kompos dan pupuk fosfor berpengaruh sangat nyata terhadap pertumbuhan tanaman kacang hijau yang meliputi parameter tinggi tanaman dan luas daun tanaman kacang hijau. Pemberian pupuk kompos dan pupuk fosfor dengan dosis 3 gram terhadap tanaman kacang hijau memberikan hasil yang sangat nyata terhadap tanaman kacang hijau yang meliputi parameter tinggi tanaman dan luas daun. Rata-rata tanaman yaitu rata-rata tinggi tanaman kacang hijau tertinggi $(32,5 \mathrm{~cm})$, rata-rata jumlah daun terbanyak (13,5 helai), dan rata-rata luas daun tertinggi $\left(24,55 \mathrm{~cm}^{2}\right)$. Sedangkan Koefisien Keragaman (KK) untuk masing-masing: tinggi sebesar $4 \%$, jumlah daun sebesar $1,96 \%$, dan luas daun sebesar 3,7\%.
\end{abstract}

\section{Kata Kunci: Pupuk Kompos, Pupuk Fosfor, Kacang Hijau}

Tanaman kacang hijau sudah lama dikenal dan ditanam oleh masyarakat tani di Indonesia. Asal usul tanaman kacang hijau diduga dari kawasan India. Nikolai Ivanovich Vavilov, seorang ahli botani Soviet, menyebutkan bahwa India merupakan daerah asal sejumlah besar suku (famili) Leguminoseae. Salah satu bukti yang mendukung pendapat Vavilov adalah ditemukannya plasma nutfah kacang hijau jenis Phaseolu mungo di India atau disebut kacang hijau India. Penyebaran kacang hijau meluas, ditanam keberbagai daerah atau negara di Asia beriklim panas (tropis), seperti Taiwan, Thailand, dan Filipina. Data AVRDC (Asian Vegetable Research and Development Center) menunjukan bahwa produksi kacang hijau dibeberapa negara Asia pada Tahun 1972-1973 amat bervariasi. India mencapai 392. 000 ton, Thailand hanya 191. 000 ton, Filipina 19. 000 ton, dan Taiwan 3. 000 ton (Rachmat Rukmana, 1997).

Kacang hijau dibawa masuk kewilayah Indonesia, terjadi pada awal abad ke-17, oleh pedagang Cina dan Portugis. Pusat penyebaran kacang hijau pada mulanya terpusat di Pulau Jawa dan Bali, tetapi pada tahun 1920-an mulai berkembang di Sulawesi, Sumatra, Kalimantan, dan Indonesia bagian Timur. Daerah sentrum produksi produksi kacang hijau adalah Propinsi Sulawesi Selatan, Jawa Timur, Nusa Tenggara Timur, Nusa Tenggara Barat, Jawa Barat, Jawa Tengah, dan DI Yogyakarta. Kacang hijau (Vigna 
radiata L.) merupakan salah satu tanaman Leguminoseae yang cukup penting. Di indonesia posisinya menduduki tempat ketiga setelah kedelai dan kacang tanah. Kacang hijau berprotein tinggi untuk dikembangkan secara intensif berpola agribisnis. Nilai ekonomis kacang hijau cukup tinggi. Pada masa yang lampau prediksi kacang hijau Indonesia memberi andil cukup berarti dalam perekonomian nasional, diantaranya diekspor kepasar internasional.

Kacang hijau tidak hanya dijadikan bahan makanan seperti bubur, taoge, makanan bayi, dan kue-kue, tetapi juga mulai digunakan sebagai makanan ternak. Pada periode tahun 1979-1987, produksi kacang hijau yang digunakan sebagai makanan ternak mencapai 18. 000 ton. Para pedagang kacang hijau di kota Ambon khususnya di Pasar Mardika biasanya hasil tanaman kacang hijau dipasok dari luar kota diakibatkan di Ambon tidak ada pembudidayaan tanaman kacang hijau. Untuk itu agar masyarakat tidak lagi memasok kacang hijau, dengan adanya penelitian ini dimaksudkan agar masyarakat Ambon dapat membudidayakan tanaman kacang hijau sendiri tanpa mengimpor hasil tanaman kacang hijau dari luar untuk diperdagangkan.

Cara bijaksana untuk membudidayakan tanaman kacang hijau ini adalah dengan menggunakan pupuk organik. Pemupukan dilakukan dengan dua cara yaitu menggunakan pupuk kompos dan pupuk fosfor. Pupuk kompos diyakini mampu meningkatkan kesuburan tanah. Pupuk fosfor memacu pertumbuhan akar dan pembentukan perakaran yang baik sehingga tanaman dapat mengambil unsur hara lebih banyak dan pertumbuhan tanaman menjadi sehat atau kuat, menggiatkan pertumbuhan jaringan tanaman yang membentuk titik tumbuh tanaman, memacu pembentukan bunga dan masaknya buah sehingga mempercepat masa panen (Anonim, 2012). Rendahnya hasil kacang hijau ditingkat petani antara lain disebabkn oleh praktek budi daya yang kurang optimal. Usaha meningkatkan produksi dan produktivitas kacang hijau dapat ditempuh dengan cara alih teknologi hasil-hasil penelitian para pakar melalui pola tanam yang serasi di daerah setempat dan didukung oleh ketersediaan varietas unggul.

\section{METODE PENELITIAN}

Tipe penelitian yang digunakan dalam penelitian ini adalah penelitian deskriptif kuantitatif dengan menggunakan metode eksperimen lapangan terhadap pertumbuhan tanaman kacang hijau. Variabel dalam penelitian ini terdiri dari:

1. Variabel bebas (x) terdiri dari : pupuk kompos dan pupuk fosfor serta interaksinya antara pupuk kompos dan pupuk fosfor

2. Variabel terikat (y) yaitu pertumbuhan tanaman dengan indikator tinggi tanaman, jumlah daun dan luas daun tanaman kacang hijau (Vigna radiata L.)

Dalam penelitian ini ada tiga percobaan yaitu percobaan untuk melihat pengaruh kompos jerami, pengaruh pupuk fosfor, dan interaksi antara pupuk kompos dan pupuk 
fosfor terhadap pertumbuhan tanaman kacang hijau. Rancangan percobaan yang digunakan adalah Rancangan Acak Lengkap faktorial dengan dua faktor perlakuan yaitu:

$\mathrm{K}_{0} \mathrm{~F}_{0}$ : tanpa pupuk kompos dan pupuk fosfor

$\mathrm{K}_{0} \mathrm{~F}_{1}$ : tanpa kompos dan fosfor 1 gram

$\mathrm{K}_{0} \mathrm{~F}_{2}$ : tanpa kompos dan fosfosr 2 gram

$\mathrm{K}_{0} \mathrm{~F}_{3}$ : tanpa kompos dan fosfor 3 gram

$\mathrm{K}_{1} \mathrm{~F}_{0}$ : kompos 1 gram dan tanpa pupuk fosfor

$\mathrm{K}_{1} \mathrm{~F}_{1}$ : kompos 1 gram dan fosfor 1 gram

$\mathrm{K}_{1} \mathrm{~F}_{2}$ : kompos 1 gram dan fosfor 2 gram

$\mathrm{K}_{1} \mathrm{~F}_{3}$ : kompos 1 gram dan fosfor 3 gram

$\mathrm{K}_{2} \mathrm{~F}_{0}$ : kompos 2 gram dan tanpa pupuk fosfor

$\mathrm{K}_{2} \mathrm{~F}_{1}$ : kompos 2 gram dan fosfor 1 gram

$\mathrm{K}_{2} \mathrm{~F}_{2}$ : kompos 2 gram dan fosfor 2 gram

$\mathrm{K}_{2} \mathrm{~F}_{3}$ : kompos 2 gram dan fosfor 3 gram

$\mathrm{K}_{3} \mathrm{~F}_{0}$ : kompos 3 gram dan tanpa pupuk fosfor

$\mathrm{K}_{3} \mathrm{~F}_{1}$ : kompos 3 gram dan fosfor 1 gram

$\mathrm{K}_{3} \mathrm{~F}_{2}$ : kompos 3 gram dan fosfor 2 gram

$\mathrm{K}_{3} \mathrm{~F}_{3}$ : kompos 3 gram dan fosfor 3 gram

Untuk lebih jelasnya perlakuan di atas maka dapat dilihat pada Tabel 1 dan Tabel 2 berikut ini:

Tabel 1. Desain Penelitian

\begin{tabular}{|c|c|c|c|c|}
\hline \multirow{2}{*}{ Faktor K } & \multicolumn{3}{|c|}{ Faktor $\mathrm{F}$} & $\mathrm{F}_{3}$ \\
\cline { 2 - 5 } & $\mathrm{F}_{0}$ & $\mathrm{~F}_{1}$ & $\mathrm{~F}_{2}$ & \\
$\mathrm{~K}_{0}$ & & & & $\mathrm{~K}_{0} \mathrm{~F}_{3}$ \\
$\mathrm{~K}_{1}$ & $\mathrm{~K}_{0} \mathrm{~F}_{0} \mathrm{~K}_{1} \mathrm{~F}_{0}$ & $\mathrm{~K}_{0} \mathrm{~F}_{1} \mathrm{~K}_{1} \mathrm{~F}_{1}$ & $\mathrm{~K}_{0} \mathrm{~F}_{2} \mathrm{~K}_{1} \mathrm{~F}_{2}$ & $\mathrm{~K}_{1} \mathrm{~F}_{3}$ \\
$\mathrm{~K}_{2}$ & $\mathrm{~K}_{2} \mathrm{~F}_{0}$ & $\mathrm{~K}_{2} \mathrm{~F}_{1}$ & $\mathrm{~K}_{2} \mathrm{~F}_{2}$ & $\mathrm{~K}_{2} \mathrm{~F}_{3}$ \\
$\mathrm{~K}_{3}$ & $\mathrm{~K}_{3} \mathrm{~F}_{0}$ & $\mathrm{~K}_{3} \mathrm{~F}_{1}$ & $\mathrm{~K}_{3} \mathrm{~F}_{2}$ & $\mathrm{~K}_{3} \mathrm{~F}_{3}$ \\
\hline
\end{tabular}

Tabel 2. Desain menurut kelompok $x$ Kombinasi Perlakuan (Kemas Ali Hanafi, 2012)

\begin{tabular}{|c|c|c|c|c|c|c|}
\hline \multirow[t]{2}{*}{ Faktor $\mathrm{K}$} & \multirow{2}{*}{$\begin{array}{c}\text { Faktor } \\
\text { F }\end{array}$} & \multicolumn{3}{|c|}{ Ulangan } & \multirow{2}{*}{$\begin{array}{c}\text { Jumlah } \\
\text { (T) }\end{array}$} & \multirow{2}{*}{$\begin{array}{c}\text { Rerata } \\
(\overline{\mathrm{y}})\end{array}$} \\
\hline & & I & II & III & & \\
\hline \multirow[t]{4}{*}{$\mathrm{K}_{0}$} & $\mathrm{~F}_{0}$ & $\mathrm{~K}_{0} \mathrm{~F}_{0} \mathrm{I}$ & $\mathrm{K}_{0} \mathrm{~F}_{0} \mathrm{II}$ & $\mathrm{K}_{0} \mathrm{~F}_{0} \mathrm{III}$ & & \\
\hline & $\mathrm{F}_{1}$ & $\mathrm{~K}_{0} \mathrm{~F}_{1} \mathrm{I}$ & $\mathrm{K}_{0} \mathrm{~F}_{1} \mathrm{II}$ & $\mathrm{K}_{0} \mathrm{~F}_{1}$ III & & \\
\hline & $\mathrm{F}_{2}$ & $\mathrm{~K}_{0} \mathrm{~F}_{2} \mathrm{I}$ & $\mathrm{K}_{0} \mathrm{~F}_{2} \mathrm{II}$ & $\mathrm{K}_{0} \mathrm{~F}_{2} \mathrm{III}$ & & \\
\hline & $\mathrm{F}_{3}$ & $\mathrm{~K}_{0} \mathrm{~F}_{3} \mathrm{I}$ & $\mathrm{K}_{0} \mathrm{~F}_{3} \mathrm{II}$ & $\mathrm{K}_{0} \mathrm{~F}_{3}$ III & & \\
\hline \multirow[t]{4}{*}{$\mathrm{K}_{1}$} & $\mathrm{~F}_{0}$ & $\mathrm{~K}_{1} \mathrm{~F}_{0} \mathrm{I}$ & $\mathrm{K}_{1} \mathrm{~F}_{0} \mathrm{II}$ & $\mathrm{K}_{1} \mathrm{~F}_{0} \mathrm{III}$ & & \\
\hline & $F_{1}$ & $\mathrm{~K}_{1} \mathrm{~F}_{1} \mathrm{I}$ & $\mathrm{K}_{1} \mathrm{~F}_{1} \mathrm{II}$ & $\mathrm{K}_{1} \mathrm{~F}_{1} \mathrm{III}$ & & \\
\hline & $\mathrm{F}_{2}$ & $\mathrm{~K}_{1} \mathrm{~F}_{2} \mathrm{I}$ & $\mathrm{K}_{1} \mathrm{~F}_{2} \mathrm{II}$ & $\mathrm{K}_{1} \mathrm{~F}_{2} \mathrm{III}$ & & \\
\hline & $\mathrm{F}_{3}$ & $\mathrm{~K}_{1} \mathrm{~F}_{3} \mathrm{I}$ & $\mathrm{K}_{1} \mathrm{~F}_{3} \mathrm{II}$ & $\mathrm{K}_{1} \mathrm{~F}_{3} \mathrm{III}$ & & \\
\hline $\mathrm{K}_{2}$ & $\mathrm{~F}_{0}$ & $\mathrm{~K}_{2} \mathrm{~F}_{0} \mathrm{I}$ & $\mathrm{K}_{2} \mathrm{~F}_{0} \mathrm{II}$ & $\mathrm{K}_{2} \mathrm{~F}_{0} \mathrm{III}$ & & \\
\hline
\end{tabular}

BIOLOGI SEL (YOL 6 NO 2 EDISI JUL-DES 2017 ISSN 2252-858X/E-ISSN 2541-1225) PAGE 150 


\begin{tabular}{|c|c|c|c|c|c|c|}
\hline & $F_{1}$ & $\mathrm{~K}_{2} \mathrm{~F}_{1} \mathrm{I}$ & $\mathrm{K}_{2} \mathrm{~F}_{1} \mathrm{II}$ & $\mathrm{K}_{2} \mathrm{~F}_{1} \mathrm{III}$ & & \\
\hline & $\mathrm{F}_{2}$ & $\mathrm{~K}_{2} \mathrm{~F}_{2} \mathrm{I}$ & $\mathrm{K}_{2} \mathrm{~F}_{2} \mathrm{II}$ & $\overline{\mathrm{K}_{2} \mathrm{~F}_{2} \mathrm{III}}$ & & \\
\hline & $\mathrm{F}_{3}$ & $\mathrm{~K}_{2} \mathrm{~F}_{3} \mathrm{I}$ & $\mathrm{K}_{2} \mathrm{~F}_{3} \mathrm{II}$ & $\mathrm{K}_{2} \mathrm{~F}_{3} \mathrm{III}$ & & \\
\hline \multirow[t]{4}{*}{$\mathrm{K}_{3}$} & $\mathrm{~F}_{0}$ & $\mathrm{~K}_{3} \mathrm{~F}_{0} \mathrm{I}$ & $\mathrm{K}_{3} \mathrm{~F}_{0} \mathrm{II}$ & $\mathrm{K}_{3} \mathrm{~F}_{0} \mathrm{III}$ & & \\
\hline & $\mathrm{F}_{1}$ & $\mathrm{~K}_{3} \mathrm{~F}_{1} \mathrm{I}$ & $\mathrm{K}_{3} \mathrm{~F}_{1} \mathrm{II}$ & $\mathrm{K}_{3} \mathrm{~F}_{1} \mathrm{III}$ & & \\
\hline & $\mathrm{F}_{2}$ & $\mathrm{~K}_{3} \mathrm{~F}_{2} \mathrm{I}$ & $\mathrm{K}_{3} \mathrm{~F}_{2} \mathrm{II}$ & $\mathrm{K}_{3} \mathrm{~F}_{2} \mathrm{III}$ & & \\
\hline & $\mathrm{F}_{3}$ & $\mathrm{~K}_{3} \mathrm{~F}_{3} \mathrm{I}$ & $\mathrm{K}_{3} \mathrm{~F}_{3} \mathrm{II}$ & $\mathrm{K}_{3} \mathrm{~F}_{3} \mathrm{III}$ & & \\
\hline \multicolumn{2}{|c|}{ Jumlah TU } & $\mathrm{T}_{\mathrm{ij}} \mathrm{I}$ & $\mathrm{T}_{\mathrm{ij}} \mathrm{II}$ & $\mathrm{T}_{\mathrm{ij}} \mathrm{IIII}$ & $T_{i j k}$ & $\overline{\mathrm{Y}}_{\mathrm{ijk}}$ \\
\hline
\end{tabular}

Data yang diperoleh dari penelitian dianalisis secara deskriptif dan analisis inverensial. Analisis deskriptif dilakukan untuk mengetahui hasil pengukuran masingmasing unit percobaan, untuk setiap pengamatan dengan menghitung rata-rata presentase dari skor kecepatan pertumbuhan. Analisis inverensial dilakukan untuk mengetahui ada tidaknya, perbedaan pengaruh pemberian kompos jerami dan pupuk fosfor (TSP) terhadap pertumbuhan tanaman kacang hijau (Vigna radiata L.) dengan model analisis sebagai berikut:

$$
\mathbf{Y}_{\mathbf{i j k}}=\boldsymbol{\mu}+\boldsymbol{\alpha} \mathbf{i}+\boldsymbol{\beta} \mathbf{j}+(\boldsymbol{\alpha} \boldsymbol{\beta}) \mathbf{i j}+\varepsilon_{\mathbf{i j k}}
$$

Jika uji-F pemberian kompos jerami dan pupuk fosfor (TSP) terhadap pertumbuhan tanaman kacang hijau (Vigna radiata L.), Maka dilanjutkan dengan uji beda dalam taraf kepercayaan $95 \%(\alpha=0,05)$ untuk melihat signifikansi pengaruhnya. Dengan koefisien keragaman $\geq 10 \%$ maka uji beda dilakukan dengan uji duncan pada taraf kepercayaan $95 \%$.

\section{HASIL DAN PEMBAHASAN}

\section{Tinggi Tanaman}

Tinggi tanaman kacang hijau saat terakhir pengukuran dapat dilihat pada tabel berikut

Tabel 3. Rata-rata Tinggi Tanaman Kacang Hijua Pada Pemberian Berbagai Dosis Pupuk

\begin{tabular}{|c|c|c|c|c|c|c|}
\hline \multirow{2}{*}{ Perlakuan } & \multicolumn{7}{|c|}{ Ulangan } & \multirow{2}{*}{ Jumlah } & \multirow{2}{*}{ Rata-rata } \\
\cline { 2 - 5 } & $\mathbf{1}$ & $\mathbf{2}$ & $\mathbf{3}$ & $\mathbf{4}$ & & \\
\hline K0F0 & 11 & 15 & 20 & 26 & 72 & 18 \\
\hline K0FI & 13,73 & 17,66 & 23,6 & 29,23 & 84,22 & 21,05 \\
\hline K0F2 & 14,16 & 18,43 & 24,46 & 30,9 & 87,95 & 21,98 \\
\hline K0F3 & 15,66 & 19,43 & 25,33 & 31,5 & 91,92 & 22,98 \\
\hline K1F0 & 16,23 & 20,26 & 26,1 & 32,5 & 95,09 & 23,77 \\
\hline K1F1 & 17 & 21,33 & 27,16 & 33,4 & 98,89 & 24,72 \\
\hline K1F2 & 17,89 & 22,16 & 27,9 & 34,66 & 102,61 & 25,65 \\
\hline K1F3 & 18 & 23,1 & 28,56 & 36,23 & 105,89 & 26,47 \\
\hline K2F0 & 18 & 23,23 & 29,2 & 36,66 & 107,09 & 26,77 \\
\hline K2F1 & 18,1 & 23,9 & 30,16 & 37,6 & 109,76 & 27,44 \\
\hline K2F2 & 18,66 & 24,6 & 31,26 & 38,33 & 112,85 & 28,21 \\
\hline K2F3 & 19,1 & 25,16 & 32,16 & 39,83 & 116,25 & 29,06 \\
\hline K3F0 & 20 & 26 & 32,66 & 40,2 & 118,86 & 29,71 \\
\hline K3F1 & 20,5 & 28 & 34,13 & 41,16 & 123,79 & 30,94 \\
\hline K3F2 & 21 & 29 & 35 & 42 & 127 & 31,75 \\
\hline K3F3 & 22 & 29 & 36 & 43 & 130 & 32,5 \\
\hline
\end{tabular}




\section{Tabel 3 menunjukan bahwa rata-rata tinggi tanaman kacang hijau tertinggi (32,5} $\mathrm{cm})$ terdapat pada perlakuan pemberiann 3 gram pupuk kompos dan 3 gram pupuk fosfor $(\mathrm{K} 3 \mathrm{~F} 3)$ dan tidak berbeda nyata dengan perlakuan $(\mathrm{K} 3 \mathrm{~F} 1$ dan $\mathrm{K} 3 \mathrm{~F} 2)$ tetapi berbeda nyata dengan perlakuan lainnya (K0F1, K0F2, K0F3, K1F0, K1F1, K1F2, K1F3, K2F0, K2F1, $\mathrm{K} 2 \mathrm{~F} 2$, $\mathrm{K} 2 \mathrm{~F} 3$, dan K3F0). Rata-rata tinggi tanaman kacang hijau terendah $(18 \mathrm{~cm})$ terdapat pada perlakuan tanpa pemberian pupuk kompos dan pupuk fosfor (K0F0) dan berbeda nyata dengan perlakuan lainnya yaitu K0F1, K0F2, K0F3, K1F0, K1F1, K1F2, K1F3, K2F0, K2F1, K2F2, K2F3, K3F0, K3F1, K3F2, dan K3F3.

Tabel 4. Tabel Anava (Tinggi Tanaman)

\begin{tabular}{|c|c|c|c|c|c|c|}
\hline $\begin{array}{c}\text { Sumber } \\
\text { Keragaman (SK) }\end{array}$ & $\begin{array}{c}\text { Derajat } \\
\text { Bebas (db) }\end{array}$ & $\begin{array}{c}\text { Junlah } \\
\text { Kuadrat } \\
(\mathbf{J K})\end{array}$ & $\begin{array}{c}\text { Kuadrat } \\
\text { Tengah } \\
(\mathbf{K T})\end{array}$ & F-hitung & & \multicolumn{2}{|c|}{ F-tabel } \\
\hline Perlakuan & $\mathbf{4 x 4 - 1}$ & $\mathbf{9 9 8 , 2 3}$ & $\mathbf{6 6 , 5 4}$ & $\mathbf{5 7 , 3 6}$ & $\mathbf{3 , 0 6}$ & $\mathbf{4 , 8 9}$ \\
\hline A & $4-1$ & 88,80 & 29,6 & $25,51^{*}$ & 9,12 & 28,71 \\
B & $4-1$ & 897,56 & 299,18 & $257,91^{* *}$ & 9,12 & 28,71 \\
AB & $(4-1)(4-1)$ & 131971,22 & 14663,46 & $12640,91^{* *}$ & 3,63 & 6,42 \\
\hline Galat & $4 \times 4(4-1)$ & 55,79 & & & & \\
\hline Total & $4 \times 4 \times 4-1$ & 133013,37 & & & & \\
\hline
\end{tabular}

Keterangan : ** berpengaruh sangat nyata

Sedangkan uji BNT (Beda Nyata Terkecil) dapat dilihat pada tabel sebagai berikut:

Tabel 5. Uji BNT (Tinggi Tanaman)

\begin{tabular}{|c|c|c|c|c|c|}
\hline \multirow[t]{2}{*}{ Perlakuan } & \multicolumn{4}{|c|}{ Ulangan } & \multirow[t]{2}{*}{ Rata-rata } \\
\hline & 1 & 2 & 3 & 4 & \\
\hline K0F0 & 11 & 15 & 20 & 26 & $18^{\mathrm{a}}$ \\
\hline K0FI & 13,73 & 17,66 & 23,6 & 29,23 & $21,05^{b}$ \\
\hline K0F2 & 14,16 & 18,43 & 24,46 & 30,9 & $21,98^{b c}$ \\
\hline K0F3 & 15,66 & 19,43 & 25,33 & 31,5 & $22,98^{\mathrm{cd}}$ \\
\hline K1F0 & 16,23 & 20,26 & 26,1 & 32,5 & $23,77^{\text {de }}$ \\
\hline K1F1 & 17 & 21,33 & 27,16 & 33,4 & $24,72^{\mathrm{ef}}$ \\
\hline K1F2 & 17,89 & 22,16 & 27,9 & 34,66 & $25,65^{\mathrm{fg}}$ \\
\hline K1F3 & 18 & 23,1 & 28,56 & 36,23 & $26,47^{\text {gh }}$ \\
\hline $\mathrm{K} 2 \mathrm{~F} 0$ & 18 & 23,23 & 29,2 & 36,66 & $26,77^{\mathrm{hi}}$ \\
\hline $\mathrm{K} 2 \mathrm{~F} 1$ & 18,1 & 23,9 & 30,16 & 37,6 & $27,44^{\mathrm{ij}}$ \\
\hline $\mathrm{K} 2 \mathrm{~F} 2$ & 18,66 & 24,6 & 31,26 & 38,33 & $28,21^{\mathrm{jk}}$ \\
\hline K2F3 & 19,1 & 25,16 & 32,16 & 39,83 & $29,06^{\mathrm{kl}}$ \\
\hline K3F0 & 20 & 26 & 32,66 & 40,2 & $29,71^{\mathrm{lm}}$ \\
\hline K3F1 & 20,5 & 28 & 34,13 & 41,16 & $30,94^{\mathrm{n}}$ \\
\hline K3F2 & 21 & 29 & 35 & 42 & $31,75^{\text {no }}$ \\
\hline K3F3 & 22 & 29 & 36 & 43 & $32,5^{\circ}$ \\
\hline \multicolumn{5}{|c|}{$\operatorname{BNT}(5 \%)=1,13$} & \\
\hline
\end{tabular}

Keterangan: Angka-angka yang diikuti oleh huruf yang sama berarti tidak berbeda nyata pada taraf 0,05. 


\section{Jumlah Daun}

Jumlah daun tanaman kacang hijau saat terakhir pengukuran dapat dilihat pada tabel berikut :

Tabel 6. Rata-rata Jumlah Daun Tanaman Kacang Hijau pada Pemberian Berbagai Dosis

\begin{tabular}{|c|c|c|c|c|c|c|}
\hline \multirow[t]{2}{*}{ Perlakuan } & \multicolumn{4}{|c|}{ Ulangan } & \multirow[t]{2}{*}{ Jumlah } & \multirow[t]{2}{*}{ Rata-rata } \\
\hline & 1 & 2 & 3 & 4 & & \\
\hline K0F0 & 4 & 7 & 10 & 13 & 34 & 8,5 \\
\hline K0F1 & 5 & 8 & 11 & 14 & 38 & 9,5 \\
\hline K0F2 & 5 & 8 & 11 & 14 & 38 & 9,5 \\
\hline K0F3 & 6 & 9 & 12 & 15 & 42 & 10,5 \\
\hline K1F0 & 6 & 9 & 12 & 15 & 42 & 10,5 \\
\hline K1F1 & 6,3 & 9 & 12 & 15 & 42,3 & 10,57 \\
\hline K1F2 & 7 & 10 & 13 & 16 & 46 & 11,5 \\
\hline K1F3 & 7 & 10 & 13 & 16 & 46 & 11,5 \\
\hline K2F0 & 6,3 & 9 & 12 & 15 & 42,3 & 10,57 \\
\hline K2F1 & 7 & 10 & 13 & 16 & 46 & 11,5 \\
\hline K2F2 & 7 & 10 & 13 & 16 & 46 & 11,5 \\
\hline K2F3 & 8 & 11 & 14 & 17 & 50 & 12,5 \\
\hline K3F0 & 8 & 11 & 14 & 17 & 50 & 12,5 \\
\hline K3F1 & 8 & 11 & 14 & 17 & 50 & 12,5 \\
\hline K3F2 & 9 & 12 & 15 & 18 & 54 & 13,5 \\
\hline K3F3 & 9 & 12 & 15 & 18 & 54 & 13,5 \\
\hline & & & & & 720,6 & 11,25 \\
\hline
\end{tabular}

Keterangan : pemberian pupuk kompos dan pupuk fosfor tidak berpengaruh nyata.

Tabel 6 menujukan bahwa jumlah daun tanaman kacang hijau terbanyak (13,5 helai) terdapat pada pemberian 3 gram pupuk kompos serta 3 gram pupuk fosfor dan 3 gram pupuk kompos serta 2 gram pupuk fosfor (K3F3 dan K3F2), jumlah tersebut lebih banyak dari perlakuan lainnya (K0F0, K0F1, K0F2, K0F3, K1F0, K1F1, K1F2, K1F3, $\mathrm{K} 2 \mathrm{~F} 0, \mathrm{~K} 2 \mathrm{~F} 1, \mathrm{~K} 2 \mathrm{~F} 2, \mathrm{~K} 2 \mathrm{~F} 3, \mathrm{~K} 3 \mathrm{~F} 0$, dan K3F1). Rata-rata jumlah daun tanaman kacang hijau terendah (8,5 helai) terdapat pada perlakuan tanpa pemberian pupuk kompos dan pupuk fosfor (K0F0), jumlah tersebut lebih rendah jika dibandingkan dengan perlakuan lainnya (K0F1, K0F2, K0F3, K1F0, K1F1, K1F2, K1F3, K2F0, K2F1, K2F2, K2F3, K3F0, K3F1, K3F2, dan K3F3).

Tabel 7. Anava (Jumlah Daun)

\begin{tabular}{|c|c|c|c|c|c|c|}
\hline $\begin{array}{c}\text { Sumber } \\
\text { Keragaman (SK) }\end{array}$ & $\begin{array}{c}\text { Derajat } \\
\text { Bebas (db) }\end{array}$ & $\begin{array}{c}\text { Junlah } \\
\text { Kuadrat } \\
(\mathbf{J K})\end{array}$ & $\begin{array}{c}\text { Kuadrat } \\
\text { Tengah } \\
(\mathbf{K T})\end{array}$ & F-hitung & & \multicolumn{2}{|c|}{ F-tabel } \\
\cline { 5 - 7 } & $\mathbf{4 x 4 - 1}$ & $\mathbf{1 2 3 , 1 4}$ & $\mathbf{4 1 , 0 4}$ & $\mathbf{0 , 0 8 3}$ & $\mathbf{3 , 0 6}$ & $\mathbf{4 , 8 9}$ \\
\hline Perlakuan & $4-1$ & 19,41 & 6,47 & $0,013^{\text {tn }}$ & 9,12 & 28,71 \\
A & $4-1$ & 100,01 & 33,33 & $0,204^{\text {tn }}$ & 9,12 & 28,71 \\
B & $(4-1)(4-1)$ & 24221,10 & 2691,23 & $-1,678^{\text {tn }}$ & 3,63 & 6,42 \\
\hline GB & $4 \times 4(4-1)$ & $-23502,64$ & & & & \\
\hline Total & $4 \times 4 \times 4-1$ & 837,88 & & & & \\
\hline
\end{tabular}

Keterangan : ${ }^{\text {tn }}$ berpengaruh tidak nyata. 


\section{Luas Daun}

Luas daun tanaman kacang hijau saat terakhir pengukuran dapat dilihat pada tabel berikut

Tabel 8. Rata-rata Luas Daun Tanaman Kacang Hijau pada Pemberian Berbagai Dosis

\begin{tabular}{|c|c|c|c|c|c|c|}
\hline \multirow{2}{*}{ Perlakuan } & \multicolumn{7}{|c|}{ Ulangan } & \multirow{2}{*}{ Jumlah } & \multirow{2}{*}{ Rata-rata } \\
\cline { 2 - 5 } & $\mathbf{1}$ & $\mathbf{2}$ & $\mathbf{3}$ & $\mathbf{4}$ & & \\
\hline K0F0 & 6,3 & 10 & 15,5 & 19,6 & 51,4 & 12,85 \\
\hline K0FI & 7,3 & 10 & 16 & 20,1 & 53,4 & 13,35 \\
\hline K0F2 & 7,6 & 11 & 17,3 & 20,6 & 56,5 & 14,12 \\
\hline K0F3 & 9 & 10,5 & 19 & 20,5 & 59 & 14,75 \\
\hline K1F0 & 10 & 10,5 & 19 & 21,5 & 61 & 15,25 \\
\hline K1F1 & 10,5 & 11,5 & 20,5 & 23,3 & 65,8 & 16,45 \\
\hline K1F2 & 11 & 12 & 21 & 24,3 & 68,3 & 17,07 \\
\hline K1F3 & 12 & 13,5 & 22,5 & 24,8 & 72,8 & 18,2 \\
\hline K2F0 & 11,3 & 13,6 & 22 & 25,6 & 72,5 & 18,12 \\
\hline K2F1 & 12,5 & 14,1 & 23 & 29 & 78,6 & 19,65 \\
\hline K2F2 & 12,7 & 14,6 & 23,5 & 30,1 & 80,9 & 20,22 \\
\hline K2F3 & 12,5 & 15,6 & 24,1 & 32,3 & 84,5 & 21,12 \\
\hline K3F0 & 13,5 & 15,6 & 25,1 & 32 & 86,2 & 21,55 \\
\hline K3F1 & 12,5 & 16 & 27 & 34,8 & 90,3 & 22,57 \\
\hline K3F2 & 13 & 17 & 28 & 36,6 & 94,6 & 23,65 \\
\hline K3F3 & 15 & 17,8 & 28,1 & 37,3 & 98,2 & 24,55 \\
\hline & & & & & $\mathbf{1 1 7 4}$ & $\mathbf{1 8 , 3 4}$ \\
\hline
\end{tabular}

Tabel 7 menunjukan bahwa rata-rata luas daun tanaman kacang hijau tertinggi $\left(24,55 \mathrm{~cm}^{2}\right)$ terdapat pada perlakuan pemberiann 3 gram pupuk kompos dan 3 gram pupuk fosfor (K3F3) dan berbeda nyata dengan perlakuan lainnya (K0F0, K0F1, K0F2, K0F3, K1F0, K1F1, K1F2, K1F3, K2F0, K2F1, K2F2, K2F3, K3F0, K3F1, dan K3F2). Ratarata luas daun tanaman kacang hijau terendah $\left(12,85 \mathrm{~cm}^{2}\right)$ tidak berbeda nyata dengan perlakuan tanpa pupuk kompos dan 1 gram pupuk fosfor (K0F1) tetapi berbeda nyata dengan perlakuan lainnya yaitu K0F2, K0F3, K1F0, K1F1, K1F2, K1F3, K2F0, K2F1, K2F2, K2F3, K3F0, K3F1, K3F2, dan K3F3.

Tabel 8. Tabel Anava (Luas Daun)

\begin{tabular}{|c|c|c|c|c|c|c|}
\hline $\begin{array}{c}\text { Sumber } \\
\text { Keragaman (SK) }\end{array}$ & $\begin{array}{c}\text { Derajat } \\
\text { Bebas (db) }\end{array}$ & $\begin{array}{c}\text { Junlah } \\
\text { Kuadrat } \\
(\mathbf{J K})\end{array}$ & $\begin{array}{c}\text { Kuadrat } \\
\text { Tengah } \\
(\mathbf{K T})\end{array}$ & F-hitung & & \multicolumn{2}{|c|}{ F-tabel } \\
\hline Perlakuan & $\mathbf{4 x 4 - 1}$ & $\mathbf{8 3 4 , 0 2}$ & $\mathbf{5 5 , 6 0}$ & $\mathbf{1 1 5 , 8 3}$ & $\mathbf{3 , 0 6}$ & $\mathbf{4 , 8 9}$ \\
\hline A & $4-1$ & 63,63 & 21,21 & $44,18^{* *}$ & 9,12 & 28,71 \\
B & $4-1$ & 768,01 & 256 & $533,33^{* *}$ & 9,12 & 28,71 \\
AB & $(4-1)(4-1)$ & 63775,03 & 7086,11 & $14762,72^{* *}$ & 3,63 & 6,42 \\
\hline Galat & $4 \times 4(4-1)$ & 23,16 & & & & \\
\hline Total & $4 \times 4 \times 4-1$ & 64629,85 & & & & \\
\hline
\end{tabular}

Keterangan : ** berpengaruh sangat nyata

Selanjutnya uji BNT (Beda Nyata Terkecil) dapat dilihat pada tabel sebagai berikut 
Tabel 9. Uji BNT (Luas Daun)

\begin{tabular}{|c|c|c|c|c|c|}
\hline \multirow[t]{2}{*}{ Perlakuan } & \multicolumn{4}{|c|}{ Ulangan } & \multirow[t]{2}{*}{ Rata-rata } \\
\hline & 1 & 2 & 3 & 4 & \\
\hline K0F0 & 6,3 & 10 & 15,5 & 19,6 & $12,85^{\mathrm{a}}$ \\
\hline K0FI & 7,3 & 10 & 16 & 20,1 & $13,35^{\mathrm{ab}}$ \\
\hline K0F2 & 7,6 & 11 & 17,3 & 20,6 & $14,12^{\mathrm{c}}$ \\
\hline K0F3 & 9 & 10,5 & 19 & 20,5 & $14,75^{\mathrm{cd}}$ \\
\hline K1F0 & 10 & 10,5 & 19 & 21,5 & $15,25^{\mathrm{de}}$ \\
\hline K1F1 & 10,5 & 11,5 & 20,5 & 23,3 & $16,45^{\mathrm{f}}$ \\
\hline K1F2 & 11 & 12 & 21 & 24,3 & $17,07^{\text {fg }}$ \\
\hline K1F3 & 12 & 13,5 & 22,5 & 24,8 & $18,2^{\mathrm{h}}$ \\
\hline K2F0 & 11,3 & 13,6 & 22 & 25,6 & $18,12^{\mathrm{h}}$ \\
\hline K2F1 & 12,5 & 14,1 & 23 & 29 & $19,65^{\mathrm{i}}$ \\
\hline K2F2 & 12,7 & 14,6 & 23,5 & 30,1 & $20,22^{\mathrm{i}}$ \\
\hline K2F3 & 12,5 & 15,6 & 24,1 & 32,3 & $21,12^{j}$ \\
\hline K3F0 & 13,5 & 15,6 & 25,1 & 32 & $21,55^{j}$ \\
\hline K3F1 & 12,5 & 16 & 27 & 34,8 & $22,57^{\mathrm{k}}$ \\
\hline K3F2 & 13 & 17 & 28 & 36,6 & $23,65^{1}$ \\
\hline K3F3 & 15 & 17,8 & 28,1 & 37,3 & $24,55^{\mathrm{m}}$ \\
\hline
\end{tabular}

Keterangan : Angka-angka yang diikuti oleh huruf yang sama berarti tidak berbeda nyata.

Pengujian hipotesis penelitian berdasar pada anggapan bahwa jika $\mathrm{F}$ hitung lebih besar dari $\mathrm{F}$ tabel maka terdapat pengaruh signifikan variabel $\mathrm{X}$ terhadap variabel $\mathrm{Y}$. Hasil analisis sidik ragam menunjukan bahwa pemberian pupuk kompos dan pupuk fosfor memberikan hasil yang sangat nyata terhadap tinggi tanaman tanaman kacang hijau. Sebagaimana yang terdapat pada tabel 4.2 dimana $F_{\text {hitung }} \mathrm{A}(25,51)>\mathrm{F}_{\text {tabel }} \mathrm{A}(9,12)$ pada taraf $(5 \%), F_{\text {hitung }} B(257,91)>F_{\text {tabel }} B(9,12)$ pada taraf $(5 \%)$, dan $F_{\text {hitung }} A B(12640,91)>$ $\mathrm{F}_{\text {tabel }} \mathrm{AB}(3,63)$ pada taraf $(5 \%)$. Oleh karena itu, hipotesis yang menyatakan bahwa ada pengaruh penggunaan pupuk kompos dan pupuk fosfor dan ada pengaruh interaksi antara pupuk kompos dan pupuk fosfor terhadap pertumbuhan tanaman kacang hijau diterima.

Hasil analisis sidik ragam menunjukan bahwa pemberian pupuk kompos dan pupuk fosfor memberikan hasil yang sangat nyata terhadap tinggi tanaman tanaman kacang hijau. Sebagaimana yang terdapat pada tabel 4.5 dimana $F$ hitung $A(0,013)<F_{\text {tabel }}$ A $(9,12)$ pada taraf $(5 \%), F_{\text {hitung }} B(-0,204)<F_{\text {tabel }} B(9,12)$ pada taraf $(5 \%)$, dan $F_{\text {hitung }} A B$ $(-1,678)>F_{\text {tabel }} \mathrm{AB}(3,63)$ pada taraf $(5 \%)$. Oleh karena itu, hipotesis yang menyatakan bahwa ada pengaruh penggunaan pupuk kompos dan pupuk fosfor dan ada pengaruh interaksi antara pupuk kompos dan pupuk fosfor terhadap pertumbuhan tanaman kacang hijau ditolak.

Hasil analisis sidik ragam menunjukan bahwa pemberian pupuk kompos dan pupuk fosfor memberikan hasil yang sangat nyata terhadap tinggi tanaman tanaman kacang hijau. Sebagaimana yang terdapat pada tabel 4.7 dimana $F_{\text {hitung }} A(44,18)>F_{\text {tabel }}$ A $(9,12)$ pada taraf $(5 \%)$, F Fitung $B(533,33)>F_{\text {tabel }} B(9,12)$ pada taraf $(5 \%)$, dan $F_{\text {hitung }}$ $\mathrm{AB}(14762,72)>\mathrm{F}_{\text {tabel }} \mathrm{AB}(3,63)$ pada taraf $(5 \%)$. Oleh karena itu, hipotesis yang menyatakan bahwa ada pengaruh penggunaan pupuk kompos dan pupuk fosfor dan ada 
pengaruh interaksi antara pupuk kompos dan pupuk fosfor terhadap pertumbuhan tanaman kacang hijau diterima.

Berdasarkan pada hasil diatas, maka Hipotesis (H0) yang menyatakan tidak ada pengaruh penggunaan pupuk kompos dan pupuk fosfor terhadap pertumbuhan tanaman kacang hijau ditolak dan hipotesis (H1) yang manyatakan ada pengaruh penggunaan pupuk kompos dan pupuk fosfor terhadap pertumbuhan tanaman kacang hijau diterima.

Pemberian berbagai dosis pupuk kompos dan pupuk fosfor memberikan hasil yang sangat nyata terhadap beberapa parameter tanaman kacang hijau yang meliputi tinggi tanaman dan luas daun. Sedangkan jumlah daun tidak memberikan hasil yang nyata. Hal tersebut didukung oleh penggunaan pupuk kompos dan pupuk fosfor. Penggunaan pupuk kompos dan pupuk fosfor sangat baik bagi pertumbuhan tanaman kacang hijau. Hal tersebut berkaitan dengan ketersediaan unsur hara bagi pertumbuhan tanaman, sehingga kesuburan tanah sangat berpengaruh. Kesuburan tanah diartikan sebagai kesanggupan untuk menyediakan unsur hara dalam jumlah cukup dan seimbang. Tetapi tidak semua tanah mampu untuk menyediakan unsur hara dalam jumlah yang cukup dan seimbang. Hal inidapat dilihat pada hasil pengamatan dengan perlakuan tanpa pemberian pupuk kompos dan pupuk fosfor (perlakuan kontrol) yang memberikan hasil terendah pada semua parameter tanaman yaitu tinggi tanaman, jumlah daun, dan luas daun. Dengan adanya perlakuan pemberian berbagai dosis pupuk kompos dan pupuk fosfor, sebagai usaha yang bertujuan untuk menambah persediaan unsur hara yang dibutuhkan oleh tanaman kacang hijau untuk meningkatkan pertumbuhan dan perkembangan serta hasil produksi tanaman.

Setyamijaja menyatakan bahwa unsur hara merupakan unsur-unsur kimia tertentu yang dibutuhkan oleh tanaman untuk pertumbuhan yang normal. Tidak tersedianya unsur hara bagi tanaman akan menyebabkan pertumbuhan terganggu, tanpaknya gejala-gejala kekurangan dan menurunnya produksi. Hasil analisis statistik menunjukan bahwa pemberian pupuk kompos dan pupuk fosfor srta interaksi antara pupuk kompos dan pupuk fosfor memberikan hasil yang sangat nyata terhadap beberapa parameter tanaman yang meliputi tinggi tanaman dan luas daun tanaman kacang hijau. Hal ini disebabkan oleh adanya penggunaan pupuk kompos dan pupuk fosfor.

Pupuk kompos adalah salah satu jenis pupuk organik yang sangat diperlukan tanaman untuk pertumbuhan, perkembangan, pembuahan dan juga untuk menjaga kesuburan tanah. Pupuk kompos merupakan hasil penguraian dari bahan-bahan organik. Pupuk kompos bermanfaat bagi penyuburan tanah. Pupuk kompos memberikan unsur hara mikro untuk melengkapi unsur hara makro yang sudah disuplai dari pupuk kimia. Dengan demikian tanaman dan tanah akan mendapatkan kelengkapan unsur hara yang diperlukan untuk tumbuh, berkembang dan berproduksi. Selain itu, kompos bermanfaat bagi pengemburan tanah. Pupuk kompos mengandung asam organik berupa asam humat yang berfungsi untuk menghancurkan bahan kimia yang tertimbun di tanah yang berasal 
dari pupuk kimia. Bahan kimia tersebut tidak bisa diserap oleh tanaman karean memang bukan berupa unsur yang diperlukan tanaman (Agus Hakim, 2012). Sedangkan pupuk fosfor memiliki peranan bagi tanaman sebagai respirasi dan fotosintesis, merangsang perkembangan akar sehingga tamana akan lebih tahan terhadap kekeringan dan mempercepat masa panen sehingga dapat mengurangi resiko keterlambatan waktu panen.

Pemberian dosis pupuk kompos dan pupuk fosfor serta interaksi antara pupuk kompos dan pupuk fosfor terhadap tanaman kacang hijau memberikan hasil yang sangat nyata pada pertumbuhan tanaman (tinggi tanaman dan luas daun). Hal ini disebabkan oleh semakin banyak dan seimbang unsur hara yang dikandung oleh tanah, semakin baik memberikan pengaruh terhadap pertumbuhan tanaman. Hal ini dapat dilihat pada pemberian 3 gram pupuk kompos dan 3 gram pupuk fosfor memberikan hasil tertinggi pada rata-rata tinggi tanaman kacang hijau tertinggi $(32,5 \mathrm{~cm})$, rata-rata jumlah daun terbanyak (13,5 helai), dan rata-rata luas daun tertinggi $\left(24,55 \mathrm{~cm}^{2}\right)$. Berdasarkan penjelasan di atas, dapat dikemukakan bahwa perlakuan pemberian pupuk kompos dan pupuk fosfor serta interaksi antara pupuk kompos dan pupuk fosfor berpengaruh sangat nyata terhadap pertumbuhan tanaman kacang hijau yang meliputi (tinggi tanaman dan luas daun tanaman kacang hijau). Sedangkan parameter pada jumlah daun tidak berpengaruh secara nyata. Penggunaan pupuk kompos dan pupuk fosfor sangat penting dalam usaha pertanian, terutama usaha uantuk meningkatkan hasil produksi tanaman kacang hijau.

\section{KESIMPULAN}

1. Pemberian pupuk kompos berpengaruh sangat nyata terhadap pertumbuhan tanaman kacang hijau (Vigna radiata L.) yang meliputi beberapa parameter tanaman antara lain tinggi tanaman dan luas daun tanaman, sedangkan parameter jumlah daun tidak berpengaruh secarat nyata.

2. Pemberian pupuk fosfor berpengaruh sangat nyata terhadap pertumbuhan tanaman kacang hijau (Vigna radiata L.) yang meliputi beberapa parameter tanaman (tinggi tanaman dan luas daun tanaman), sedangkan parameter jumlah daun tidak berpengaruh secara nyata.

3. Interaksi antara pupuk kompos dan pupuk fosfor memberikan pengaruh sangat nyata terhadap pertumbuhan tanaman kacang hijau (Vigna radiata L.) yang meliputi beberapa parameter tanaman antara lain tinggi tanaman dan luas daun tanaman, sedangkan pada parameter jumlah daun tidak berpengaruh secara nyata.

4. Pemberian pupuk kompos dan pupuk fosfor dengan dosis 3 gram terhadap tanaman kacang hijau memberikan hasil yang sangat nyata pada pertumbuhan tanaman kacang hijau yang meliputi beberapa parameter antara lain tinggi tanaman dan luas daun tanaman. Rata-rata tinggi tanaman kacang hijau tertinggi $(32,5 \mathrm{~cm})$, rata-rata jumlah daun terbanyak (13,5 helai), dan rata-rata luas daun tertinggi $\left(24,55 \mathrm{~cm}^{2}\right)$. Sedangkan 
Koefisien Keragaman (KK) untuk masing-masing: tinggi sebesar 4\%, jumlah daun sebesar $-1,96 \%$, dan luas daun sebesar $3,7 \%$.

\section{SARAN}

1. Budidaya tanaman kacang hijau sebaiknya dengan memberikan pupuk kompos dan pupuk fosfor dengan dosis 3 gram agar mampu memberikan pengaruh yang lebih baik pada pertumbuhan dan hasil produksi tanaman.

2. Penggunaan pupuk kompos dan pupuk fosfor perlu dilakukan secara teratur agar tidak menghambat pertumbuhan tanaman.

\section{DAFTAR PUSTAKA}

Anwar, Desi. 2002. Kamus Lengkap Bahasa Indonesia. Surabaya: Amelia.

Apriadji. 2004. Memproses Sampah. Jakarta: Penebar Swadaya.

Badan Litbang Pertanian. 1983. Laporan Tahunan 1987. Departeme Pertanian.

BIP Lembaga Jawa Barat. Tanpa Tahun. Budidaya Kacang Hijau. Dalam Liptan No. 10, Agustus 1988.

Budhi Susanto Radjit. "Uji Paket Teknologi Budidaya Kacang Hijau pada Derah Potensial untuk Pengembangan." Dalam "Teknologi Untuk Menunjang Peningkatan Produksi Tanaman Pangan”. Balittan Pangan, Malang. 1933.

Departemen Pertanian. 2004. Petunjuk Pemupukan yang Efektif. Jakarta: PT Agromedia Pustaka.

Habibi, Lafran. 2009. Pembuatan Pupuk Kompos Dari Limbah Rumah Tangga. Bandung: Titian Ilmu, Bandung.

Isro, dan Yuliarti Nurheti. Kompos. 2009. Cara Mudah, Murah \& Cepat Menghasilkan Kompos. Jakarta: C. V ANDI OFFSET.

Khozien. 1990. Mulsa pada Tanaman Kacang Hijau. Jakarta: Sinar Tani.

Purwono dan Heni Purnamawati. 2007. Budi Daya 8 Jenis Tanaman Pangan Unggul. Bogor: Penebar Swadaya.

Peneliti Balai Pengkajian Teknologi Pertanian (PBPTP). 2007. Teknologi Budi Daya Kacang Hijau (Vigna radiata L.) di Lahan Sawah. Jurnal Ilmiah Tambua, Vol. VI, No. 1. Sumatra Barat.

Rukmana, H. R. 1996. Kacang Hijau: Budi Daya \& Pasca Panen. Jakarta: Agro Pustaka. Soedjono. 1995. Seri Industri Pertanian. Bandung: PT Remaja Rosdakarya.

Tony Lukman Lutoni. "Kacang Hijau, Kecil Tapi Menguntungkan.” Dalam "Pikiran Rakyat” Januari, 1990.

Hanafiah K.A. 2012. Rancangan Percobaan, Teori dan Aplikasi. Jakarta: Raja Grafindo Persada

Handayandi, Tri. 1994. Pentingnya Jarak Tanam dan Varietas Unggul dalam Peningkatan Hasil Kacang Hijau. Jakarta: Sinar Tani 